\title{
Managing Sand Along the Colorado River to Protect Cultural Sites Downstream of Glen Canyon Dam
}

T The construction of Glen Canyon Dam in northern Arizona has greatly reduced the supply of sand to the Colorado River corridor through Glen Canyon National Recreation Area and Grand Canyon National Park, hereafter referred to as Glen Canyon and Grand Canyon, respectively. This deficit has strongly affected the natural sediment cycle in this iconic landscape and has lowered the availability of windblown (aeolian) river sand that previously shielded hundreds of unique prehistoric and historic cultural sites. U.S. Geological Survey scientists and their cooperators have conducted a range of studies to assess whether, and under what circumstances, riverderived sand can still reach and protect these sites under

Cover spread. Photographs of a windblown (aeolian) dune adjacent to a sandbar before (inset) and after vegetation removal conducted by the National Park Service, which is intended to increase aeolian sand transport inland from the river, toward the right side of the photograph. U.S. Geological Survey photographs by Joel B. Sankey. current dam operations. Results indicate that most cultural sites hosted in river-derived sand have an elevated risk of erosion that threatens their long-term preservation. However, repeated high-water releases from the dam following downstream tributary inputs of sand to the Colorado River, combined with riparian vegetation removal, could offset some of the erosion caused by wind and precipitation-driven hillslope runoff at some locales. These findings are helping managers conserve limited sand resources to preserve river-corridor cultural sites while still meeting the growing demands for hydropower and water in the Southwestern United States.

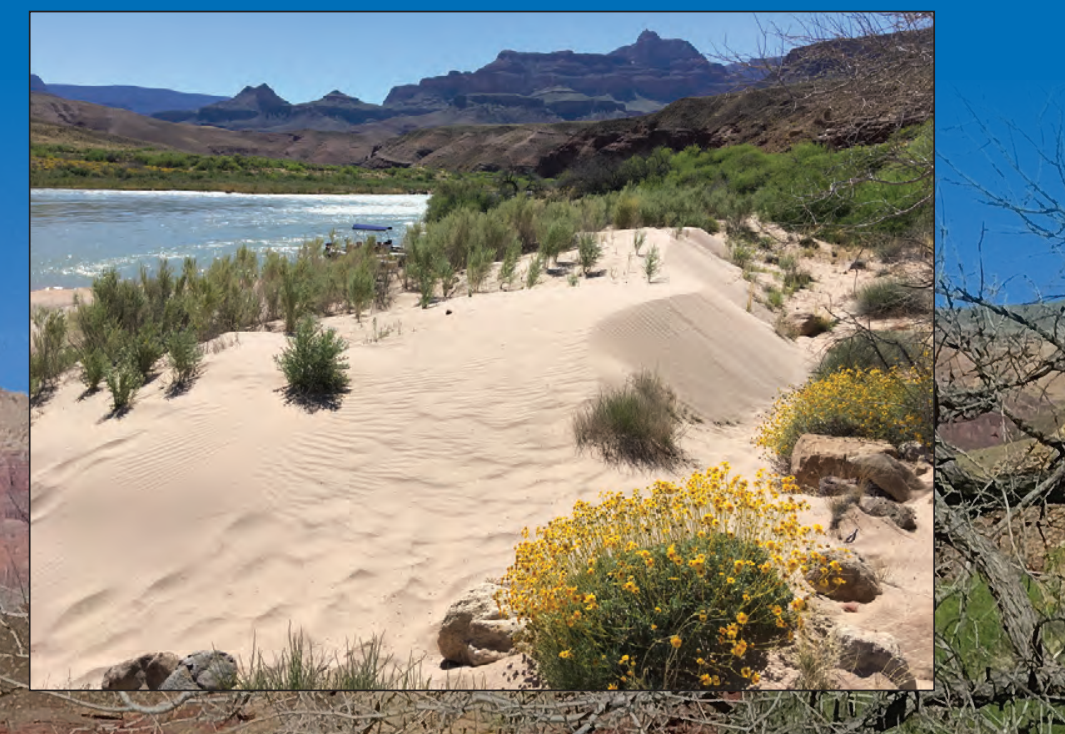




\section{Background}

Glen Canyon Dam, located 15 miles upstream of Arizona's Grand Canyon National Park, regulates the Colorado River and supplies hydropower and water to nearly 40 million people in the arid Southwest. Prior to the dam's completion in 1963, spring snowmelt regularly swelled the river. These floods transported such large loads of sediment eroded from the soft red rocks upstream that early Spanish explorers named it the "colored" river -El Río Colorado.

Today, the river typically carries little to no suspended sediment below Glen Canyon Dam unless downstream tributaries such as the Paria River flood, as happens in the summer monsoon season. This is because the dam's reservoir, Lake Powell, traps all the upstream river sediment, including the large volumes of sand that once sustained the Colorado River corridor's distinctive sandbars, terraces, and aeolian dune fields. These landforms, and the native plants and animals they host, are intrinsic components of the river corridor ecosystem, which includes the lower 15 miles of Glen Canyon immediately downstream of the dam as well as the 277-mile-long Grand Canyon downstream of Lees Ferry. However, many of these sandbars have eroded or become overgrown with riparian vegetation since the completion of Glen Canyon Dam.

The increasing scarcity of unvegetated river sandbars is of particular concern because these features comprise important wildlife habitat, provide camping beaches for hikers and whitewater rafters, and are primary sources of the windblown sand that historically covered and protected many of the culturally important sites found along the river corridor. In response to the effects of Glen Canyon Dam on downstream cultural, natural, and recreational resources, Congress enacted the Grand Canyon Protection Act of 1992 to "protect, mitigate adverse impacts to, and improve the values for which Grand Canyon National Park and Glen Canyon National Recreation Area were established." Tributaries downstream of Glen Canyon Dam, such as the Paria River, supply less than 16 percent of Grand Canyon's average pre-dam supply of sand, making the remaining limited sand resources that help preserve the corridor's irreplaceable cultural sites a priority.

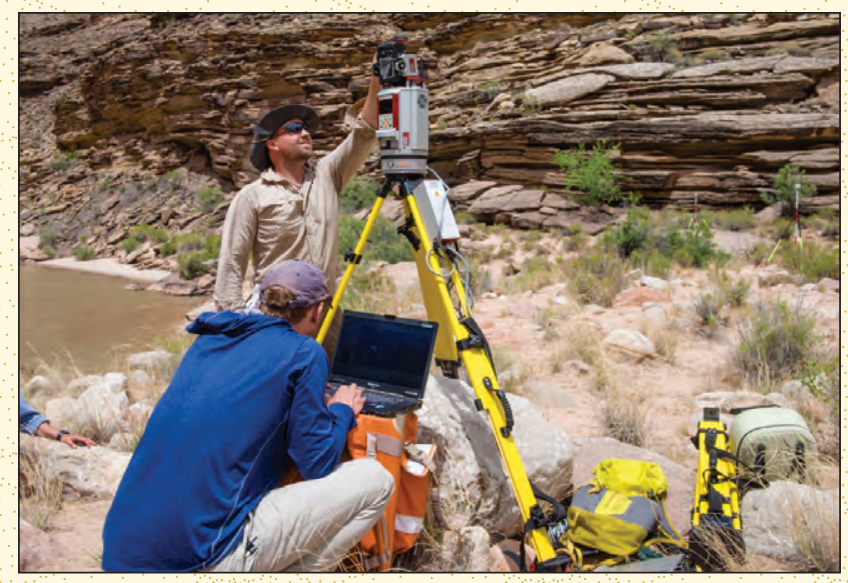

Photograph showing lidar survey setup used to help quantify erosion and deposition of sediment at cultural sites throughout the Colorado River corridor U.S. Geological Survey photograph by Alan Fairley.

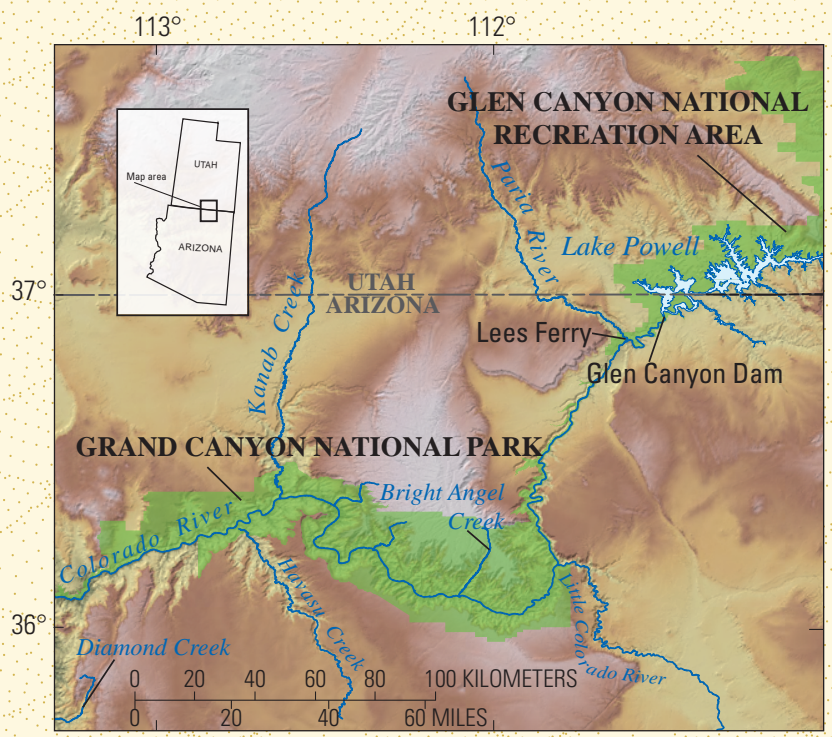

Map of the Lower Colorado River Basin showing the river corridor downstream of Lake Powell.

\section{Informing Adaptive Management}

To fulfill the obligations of the Grand Canyon Protection Act, the Federal Government established the Glen Canyon Dam Adaptive Management Program (GCDAMP). This Federal advisory committee of 25 diverse stakeholders utilizes feedback from long-term scientific monitoring to recommend modifications to dam operations that improve the condition of archaeological sites and other downstream resources. Controlled floods, termed "highflow experiments" (HFEs, described in http://pubs usgs. gov/fs/2011/3012/), are one such modification of dam operations. HFEs involve intentionally releasing higherthan-normal peak flows of water from the dam for limited periods to redistribute riverbed sand to higher shoreline areas throughout the river corridor. Field studies following HFEs, which began in 1996, indicate that these events are successful in resupplying sandbars. This is especially true when HFEs are conducted shortly after natural floods in one or more tributaries that have delivered a load of new sand to the mainstem channel downstream of the Glen Canyon Dam.

Because of these findings, GCDAMP stakeholders recommended that the Secretary of the Interior adopt a new experimental dam operating protocol in 2012. As long as several environmental conditions are met, managers are allowed to conduct dam-controlled HFEs up to 45,000 cubic feet per second to redistribute tributary sand and help rebuild eroded sandbars up to two times per year. This approach was carried forward by the Department of Interior's 2016 Long-Term Experimental and Management Plan, a 20-year plan guiding Glen Canyon Dam operations (U.S. Department of the Interior, 2016).

Scientists at the U.S. Geological Survey (USGS) lead the research and monitoring activities that document the results of these HFEs and inform adaptive management decisions. This research has recently focused on two crucial questions: Are river corridor archaeological sites more susceptible to erosion under current dam operations? Can annual, dam-controlled HFEs redistribute enough tributary sand to improve the preservation of downstream archaeological sites? 


\section{Glen Canyon Dam high-flow experiments (HFEs)}

\section{Before water release}

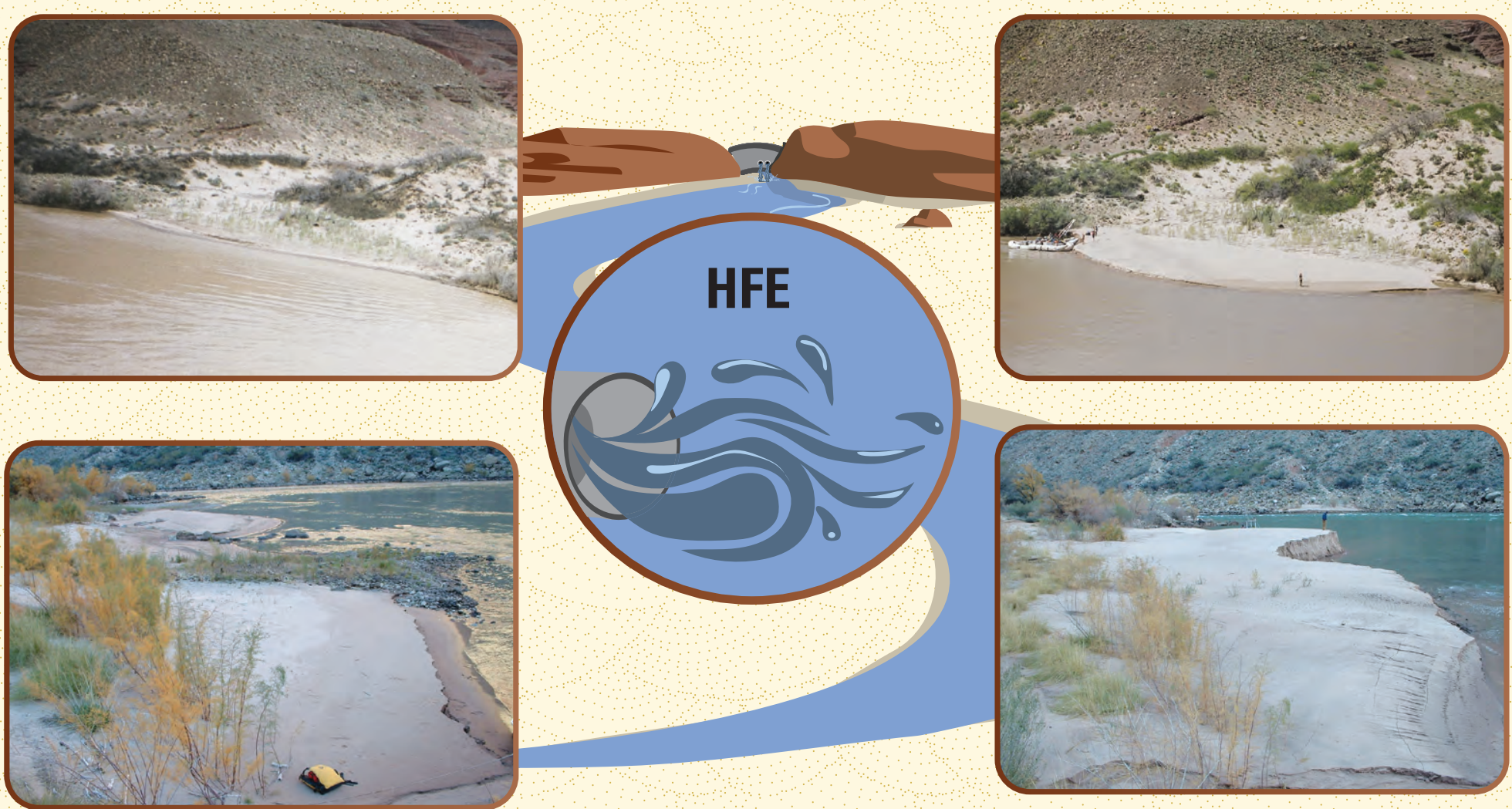

HFEs are controlled floods that involve intentionally releasing higherthan-normal peak flows of water from Glen Canyon Dam for limited periods to redistribute riverbed sand to sandbars and other higher elevation shoreline areas throughout the river corridor. Photos taken before and after HFEs show sandbar growth as a result of the higher flow. U.S. Geological Survey photographs by Amy East.

\section{Cultural Sites}

The Colorado River transects the high and arid Colorado Plateau and forms a long, narrow oasis whose natural resources have attracted humans for at least 7,000 years. While visiting the river and its tributaries to seek water and sustenance, native people left tangible traces of their presence. Hundreds of prehistoric sites display evidence of human modification, including masonry dwellings, ditches, fields, seasonal campsites, petroglyphs, roasting pits, and quarries. Additionally, numerous historical sites such as mining locations and river-runner camps also constitute an integral part of the river corridor's history.

Many archaeological sites, as well as springs and other places of traditional importance, hold special meaning for the 11 Native American tribes that have traditional and ongoing ties to the Grand Canyon region. Six of these tribes - the Hopi, Hualapai, Navajo, Kaibab Band of Paiute Indians, Paiute Indian Tribe of Utah, and the Pueblo of Zuni-actively participate in the GCDAMP. All of these tribes consider Grand Canyon part of their traditional homeland as well as a sacred landscape that should be protected from adverse human impacts. Yet preserving these cultural resources in this dynamic terrain has proven challenging for the National Park Service, who administers the sites.

\section{A Changing Landscape}

The Colorado River corridor is a dynamic landscape shaped by a combination of river, aeolian, and hillslope processes. For thousands of years, floods have carried and deposited new sand in terraces and bars along the river channel of Glen and Grand Canyons. Between floods, winds redistributed much of this material to create a patchwork of river-derived sand deposits throughout the riparian corridor and adjacent desert.

Because most of the cultural resources located along the Colorado River in Glen and Grand Canyons are situated in or on top of this loose, sandy material, they are vulnerable to weathering and erosion. Prior to river regulation, a blanket of sand as much as several meters thick shielded many archaeological sites from the elements as well as from visitor impacts. The modern dam-controlled river no longer produces the large, sediment-rich floods that replenish terraces and dune fields and sweep away vegetation. Some cultural sites have become more exposed, and thus susceptible to further erosion and visitor impacts.

Ultimately, the stability of these deposits depends upon whether the deposition of sand can outpace the erosion occurring at each location. Under the National Historic Preservation Act of 1966 and other applicable legislation, Federal managers are required to reduce or mitigate the effects of dam operations on Colorado River cultural resources and to prioritize preserving those resources in place. 


\section{Gully Erosion}

Along the arid Colorado River corridor, runoff generated from intense rainstorms, particularly during the summer monsoon season, can flow vigorously across the landscape. In places where it intersects sand, runoff can downcut through river terraces to create and enlarge gullies. In other areas, particularly in Grand Canyon, largescale mapping by USGS scientists has shown that aeolian sand seems capable of limiting or even counteracting this intense erosion by infilling incipient gullies. But recent studies have also indicated that gully infilling has been occurring less frequently as the amount of sand that the river delivers has declined.

Erosive runoff and gully infilling have the potential to both degrade and mitigate damage to cultural sites in Glen and Grand Canyons. USGS scientists conducted field studies and aerial-photograph appraisals to characterize changes in gully configuration at each river-corridor archaeological site. The results indicated that the majority of cultural sites, including nearly every locale in Glen Canyon, have gullies running through or adjacent to them. In many cases, the formation of these gullies has damaged archaeological resources (East and others, 2017).

In sand-starved Glen Canyon, the majority of affected archaeological sites are intersected by gullies that lead to the mainstem river channel. By contrast, about 20 percent of the locations have gullies graded to higher, pre-dam terraces. Through this analysis, USGS researchers identified several examples of cultural sites where gullies had begun to grade to a lower level - a change that could signal a transition to a more degraded condition and therefore warrant more detailed monitoring.

\section{Assessing Modern Sand Supplies}

To assess the potential for river-derived, wind-blown sand to offset erosion at cultural resources, USGS scientists evaluated aeolian sand supplies upwind of hundreds of archaeological sites in Glen and Grand Canyons. These include sites above the contemporary 45,000 cubic feet per second high-water line. Using historical photographs, field observations, and several years of wind measurements, researchers demarcated upwind sand sources. They also determined the direction of locally prevailing winds and located intervening vegetation and topographic barriers to aeolian transport. The scientists then used these data to assess the likelihood that windblown sand could replenish the sand cover at each cultural site.

The results of this assessment indicated that approximately 37 percent of the Grand Canyon's sand-hosted archaeological sites formerly were ideally situated to receive windblown sand, whereas today only 12 percent are well situated to receive sand from active sandbar. sources. This change appears to be primarily caused by a combination of three river-regulation factors: (1) a reduction in the size of sand bars deposited along the shoreline under dam-regulated flows, (2) the absence of sedimentrich floods larger than 45,000 cubic feet per second to deliver sand above the contemporary high-water line, and (3) an increase in the amount of riparian vegetation growing along the shoreline (East and others, 2016). This vegetation has reduced the availability of open sandbars as source areas for wind-blown sand and has also created physical barriers to the transport of sand by wind from the river's edge to inland areas.

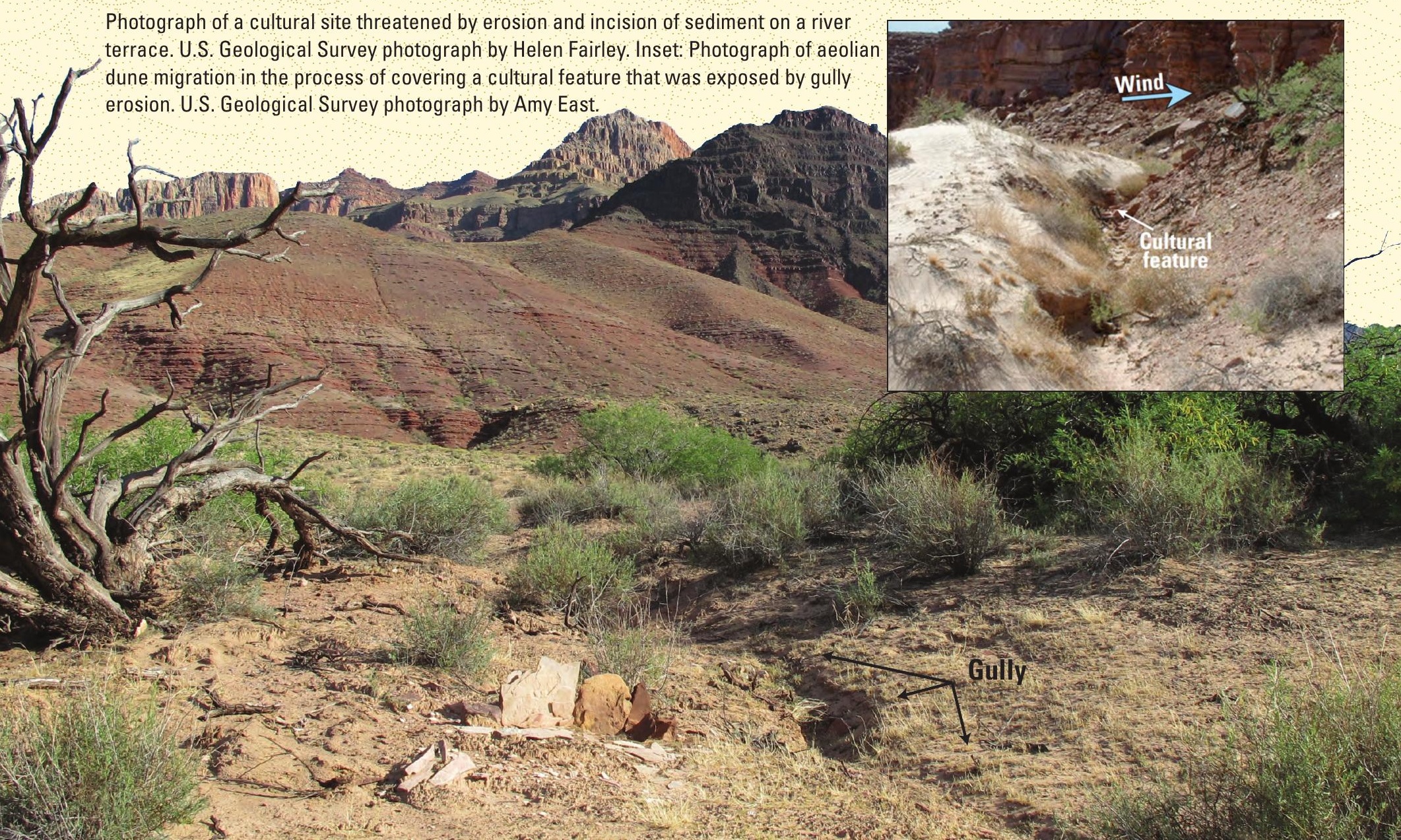




\section{Managing the Sand Balance at Cultural Sites}

In Glen and Grand Canyons, even archaeological sites with a high degree of connectivity to active sources of aeolian sand may still be susceptible to damage by wind, rain, gullying, and slope movements that are continually reshaping the landscape. The long-term protection of these cultural resources therefore depends upon the volume of sand each site receives relative to the volume removed by erosive forces.

To better understand this delicate balance, starting in 2007, USGS scientists began conducting repeat, highresolution laser topographic (lidar) surveys to measure the rates and amounts of erosion and deposition occurring at cultural sites throughout the river corridor. Initial results indicated that more sand was removed than deposited during the 2007-2012 monitoring period.

Beginning in 2012, at the start of the new HFE protocol, repeat lidar surveys focused on two end-member groups of archaeological sites. These consisted of four sites in Grand Canyon that are connected to active sources of windblown sand and another four in Glen Canyon with no modern sand supply. Although the rates of annual erosion were similar at all eight cultural sites, a relative lack of sand deposition at the four Glen Canyon locales resulted in greater net erosion. Initially, these findings suggested that under current dam operations, there might not be enough short-term sand deposition to preserve many cultural resources. This appeared to be true even at the small percentage of archaeological sites where aeolian sand supplied by annual HFEs was being actively deposited. However, as USGS scientists continued to monitor the four Grand Canyon locales, they measured cumulative and consistent increases in the amount of sand within dune fields hosting archaeological sites whenever high flows were conducted consecutively each year under the HFE protocol (Sankey and others, 2018). There are at least 117 dune fields and other large areas of aeolian, river-derived sediment, many of which could be cumulatively replenished by HFEs. Whereas many of these areas contain documented archaeological sites, some may also contain undocumented sites that have been buried for decades or centuries.

Collectively, the research findings to date indicate that most river-corridor archaeological sites in Glen and Grand Canyons have an elevated risk of erosion under current dam operations. However, the results also suggest a mechanism to improve the preservation potential of some sites that are connected via aeolian transport from HFE sandbars (Sankey and others, 2018). Because the amount of native and nonnative riparian vegetation, which impedes aeolian transport, has expanded in the absence of large, scouring floods, targeted vegetation removal could also potentially increase the amount of sand available for redistribution onto cultural sites.

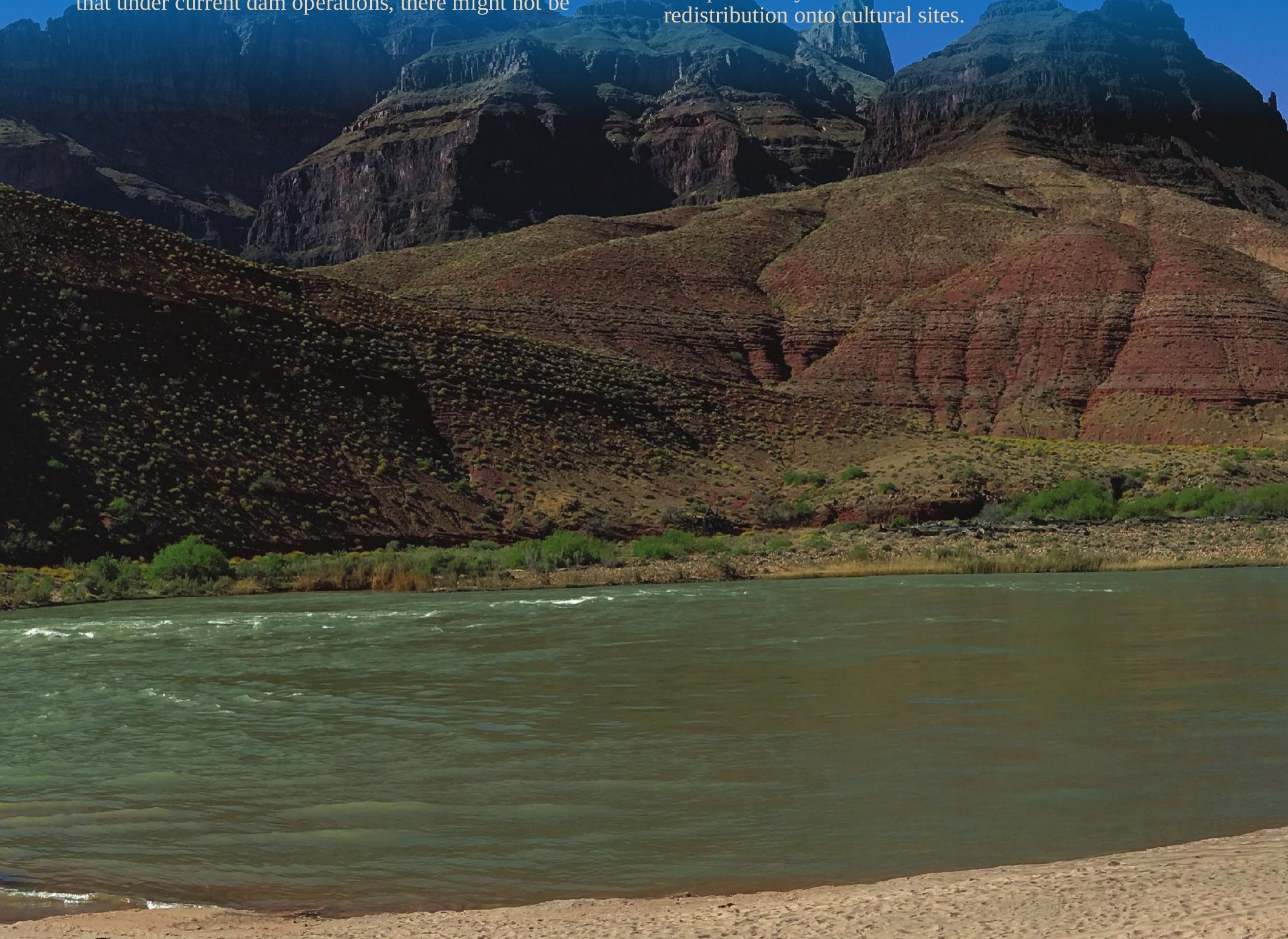


